\title{
Energy landscapes shape microbial communities in hydrothermal systems on the Arctic Mid-Ocean Ridge
}

\author{
Håkon Dahle ${ }^{1,2}$, Ingeborg Økland ${ }^{1,3}$, Ingunn $\mathrm{H}_{\text {Thorseth }}^{1,3}$, Rolf B Pederesen ${ }^{1,3}$ \\ and Ida H Steen ${ }^{1,2}$ \\ ${ }^{1}$ Centre for Geobiology, University of Bergen, Bergen, Norway; ${ }^{2}$ Department of Biology, University of Bergen, \\ Bergen, Norway and ${ }^{3}$ Department of Earth Science, University of Bergen, Bergen, Norway
}

\begin{abstract}
Methods developed in geochemical modelling combined with recent advances in molecular microbial ecology provide new opportunities to explore how microbial communities are shaped by their chemical surroundings. Here, we present a framework for analyses of how chemical energy availability shape chemotrophic microbial communities in hydrothermal systems through an investigation of two geochemically different basalt-hosted hydrothermal systems on the Arctic Mid-Ocean Ridge: the Soria Moria Vent field (SMVF) and the Loki's Castle Vent Field (LCVF). Chemical energy landscapes were evaluated through modelling of the Gibbs energy from selected redox reactions under different mixing ratios between seawater and hydrothermal fluids. Our models indicate that the sediment-influenced LCVF has a much higher potential for both anaerobic and aerobic methane oxidation, as well as aerobic ammonium and hydrogen oxidation, than the SMVF. The modelled energy landscapes were used to develop microbial community composition models, which were compared with community compositions in environmental samples inside or on the exterior of hydrothermal chimneys, as assessed by pyrosequencing of partial 16S rRNA genes. We show that modelled microbial communities based solely on thermodynamic considerations can have a high predictive power and provide a framework for analyses of the link between energy availability and microbial community composition.
\end{abstract}

The ISME Journal (2015) 9, 1593-1606; doi:10.1038/ismej.2014.247; published online 9 January 2015

\section{Introduction}

How microbial communities are shaped by environmental conditions has been extensively studied during the past decades. Numerous efforts have been made to assess the effect of directly measurable environmental parameters, such as temperature, salinity and concentrations of single chemical species. However, the question of to what extent energy availability determines the structure of chemotrophic microbial communities has received little attention. Nevertheless, as all life forms require an energy source, energy availability must constrain the distribution of functional groups of organisms in any biological community.

Marine and terrestrial hydrothermal systems represent in many ways excellent natural laboratories for the exploration of how energy landscapes shape communities of chemotrophic microorganisms. Indeed, energy availabilities from redox reactions have

Correspondence: H Dahle, Centre for Geobiology, University of Bergen, Allegaten 41, 5007 Bergen, Norway.

E-mail: Hakon.Dahle@bio.uib.no

Received 25 April 2014; revised 17 November 2014; accepted 21 November 2014; published online 9 January 2015 been extensively analysed in deep sea (McCollom and Shock, 1997; McCollom, 2000, 2007; Amend et al., 2011), shallow sea (Amend et al., 2003; Rogers and Amend, 2005, 2006; Rogers et al., 2007) and terrestrial hot spring environments (Meyer-Dombard et al., 2005; Spear et al., 2005; Shock et al., 2010). In particular, terrestrial hot springs offer the opportunity to link in situ energy availabilities, derived from in situ chemical analyses, with observed microbial communities. However, it is also evident that attempts to reveal the connections between energy availability and microbial community composition in hot springs are made difficult by the general high number of organisms with unknown metabolic capabilities in these habitats (see for example, Rogers and Amend, 2005). Also, phototrophic organisms often dominate under mesophilic to moderately thermophilic conditions in terrestrial hydrothermal systems, complicating the assessment of how microbial communities are shaped by available chemical energy sources under these conditions.

In marine hydrothermal systems, hot and reduced hydrothermal fluids (HFs) enriched in potential electron donors (e.g. $\mathrm{H}_{2} \mathrm{~S}, \mathrm{CH}_{4}, \mathrm{H}_{2}$ ) mix with cold seawater (SW), which is rich in potential electron 
acceptors (e.g. $\mathrm{O}_{2}, \mathrm{SO}_{4}^{2-}$ ). Consequently, chemical metastable disequilibria are formed, which can be used as energy sources by mesophilic to hyperthermophilic chemotrophic primary producers (Jannasch and Mottl, 1985; McCollom and Shock, 1997). Fluid mixing may occur in hydrothermal chimney walls, hydrothermal sediments and hydrothermal plumes forming in the water column above the vent fields. Energy landscapes and metabolic rates in these types of habitats have been assessed through modelling based on the chemical endmember composition of $\mathrm{HFs}$ and ambient SW (Tivey, 1995; McCollom and Shock, 1997; McCollom, 2000, 2007; Shock and Holland, 2004; Amend et al., 2011; LaRowe et al., 2014). However, it should be emphasized that a detailed understanding of how energy landscapes shape microbial communities are hampered by the lack of integrated studies that combine models and field observations (Houghton and Seyfried, 2010). Also, although modelled energy landscapes have been used as a framework for general predictions of the distribution of functional groups of microorganisms in hydrothermal systems, models of community composition based on thermodynamic calculations have so far not been established. In this study, we develop such models and assess their predictive power based on Bray-Curtis dissimilarities (BCDs) between modelled and observed communities in two vent fields at the Arctic Mid-Ocean Ridge in the NorwegianGreenland Sea. In addition, we report for the first time a dominance of the Crenarchaeotal MCG and the anaerobic methanotrophic archaea group (ANME-1) in hydrothermal chimneys under thermophilic conditions.

\section{Materials and methods}

Geological settings and fluid chemistry

The Arctic Mid-Ocean Ridge, which consists of several ridge segments north of Iceland, is one of the most slow-spreading ridge systems on the Earth. In 2005 the two first active deep-sea hydrothermal fields on this system, the Troll Wall $\left(71^{\circ} 17^{\prime} \mathrm{N}\right.$, $\left.05^{\circ} 46^{\prime} \mathrm{W}\right)$ and the Soria Moria $\left(71^{\circ} 15^{\prime} \mathrm{N}, 05^{\circ} 49^{\prime} \mathrm{W}\right)$ Vent Fields, were discovered at the southwestern part of the Mohns ridge, only about $5 \mathrm{~km}$ apart from each other and at a depth of 500 and $700 \mathrm{~m}$, respectively (Figure 1) (Pedersen et al., 2010a). Both fields contain numerous white smoker chimneys venting fluids up to $270^{\circ} \mathrm{C}$. In 2008 another field, the Loki's Castle Vent Field (LCVF) $\left(73^{\circ} 33^{\prime} \mathrm{N}\right.$, $08^{\circ} 09^{\prime} \mathrm{W}$ ), was discovered further north where the Mohns Ridge passes into the Knipovich Ridge, at around $2400 \mathrm{~m}$ water depth (Pedersen et al., 2010a, b). This field has four major black smoker chimneys venting fluids with a temperature of $305-317^{\circ} \mathrm{C}$. All the vent fields are basalt hosted, and the sulphide concentrations of their venting fluids are comparable. However, the much higher concentrations of hydrogen, methane and ammonium in the LCVF fluids indicate influence of buried sediments that have been transported into the rift valley from the adjacent Bear Island Fan (Pedersen et al., 2010a, b). Since the discovery of the vent fields, the endmember composition has been spatially and temporally stable within both LCVF (Pedersen et al., 2010b) and SMVF (unpublished data), indicating single sources. The fluid compositions used in this study are given in Table 1. Dissolved oxygen was measured with an oxygen microsensor (PreSens Precision Sensing GmbH, Regensburg, Germany). Nitrate was analysed colourmetrically by a Quaatro continuous flow analyser (SEAL Analytical Ltd, Southampton, UK). All other values were taken from Baumberger (2011) and Pedersen et al. (2010b).

\section{Sampling}

All samples (Table 2) were collected using a remotely operated underwater vehicle (ROV). Three biofilms, growing on the exterior of the 'João' chimney wall (ROV3 and ROV4) and the 'Camel' chimney wall (ROV9) in the LCVF, were sampled in 2009 with a hydraulic pump device, which was rinsed thoroughly with sterile $\mathrm{dH}_{2} \mathrm{O}$ between subsequent dives (Figures 2a-c). $16 \mathrm{~S}$ rRNA gene sequence data for ROV3 and ROV4 were taken from Dahle et al. (2013), and are reanalysed here. A flange structure on a chimney in the SMVF was collected in 2011 using a shuffle box (Figure 2). After arrival on the ship, four subsamples (F1-F4) were taken from the dark, highly porous and sulphide-rich lower part of the flange (distances from the lower outside: F1, 0-1 cm; F2, 2-6 cm; F3, 7-11 cm; F4, $13-18 \mathrm{~cm})$. The total vertical thickness of the flange at the sampling site was $21 \mathrm{~cm}$. One sample of lighter greyish anhydrite-rich material (W1) was taken from the central part of the transition between the flange and the chimney wall. Each flange subsample $(\sim 5 \mathrm{~g})$ was crushed and homogenized in a mortar, and stored at $-80^{\circ} \mathrm{C}$ before further processing. In situ temperatures were measured with an ROV-held temperature probe.

\section{DNA extraction and PCR}

Total DNA was extracted using the FastDNA spinkit for soil (MP Biomedicals, Santa Ana, CA, USA). Amplification of 16S rRNA genes was performed, as described previously (Roalkvam et al., 2011), using a two-step PCR approach. The first PCR step was performed with $<20 \mathrm{ng}$ template in 25-33 cycle reactions using primers universal for Archaea and Bacteria-Un787f (5'-ATTAGATACCCNGGTAG-3') (Roesch et al., 2007) and Un1392r (5'-ACGGGC GGTGWGTRC-3') (modified from Lane et al., 1985). To minimize PCR bias, reactions were run in triplicates, which were pooled and rinsed with the MinElute PCR Purification Kit (Qiagen). In the second PCR step, 20 ng PCR product from the first PCR was 


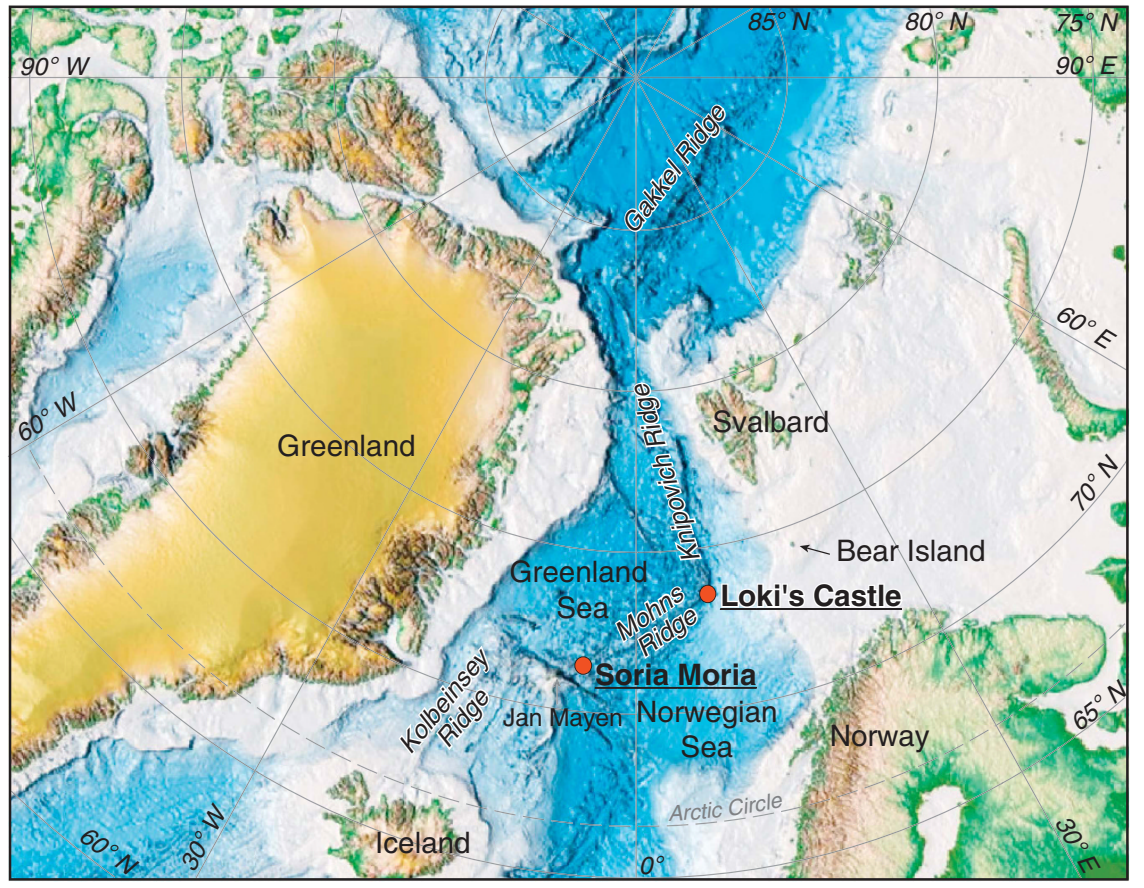

Figure 1 Map showing the location of the Soria Moria and the LCVFs.

Table 1 Chemical composition of vent fluids (endmember) and seawater used in this study

\begin{tabular}{|c|c|c|c|c|c|c|c|c|c|c|c|c|c|}
\hline $\begin{array}{l}\text { Hydrothermal } \\
\text { system }\end{array}$ & $\begin{array}{c}\mathrm{T} \\
\left({ }^{\mathrm{T}} \mathrm{C}\right)\end{array}$ & $p H$ & $\begin{array}{l}\mathrm{Na}^{+} \\
(\mathrm{mm})\end{array}$ & $\begin{array}{l}C a^{2+} \\
(\mathrm{mm})\end{array}$ & $\begin{array}{c}K^{+} \\
(\mathrm{mm})\end{array}$ & $\begin{array}{l}\mathrm{Fe}^{2+} \\
(\mu \mathrm{m})\end{array}$ & $\begin{array}{c}\mathrm{Cl}^{-} \\
(\mathrm{mm})\end{array}$ & $\begin{array}{l}\mathrm{SiO}_{2} \\
(\mathrm{~mm})\end{array}$ & $\begin{array}{c}\mathrm{CH}_{4} \\
(\mathrm{~mm})\end{array}$ & $\begin{array}{l}\mathrm{H}_{2} \mathrm{~S} \\
(\mathrm{~mm})\end{array}$ & $\begin{array}{c}\mathrm{H}_{2} \\
(\mathrm{~mm})\end{array}$ & $\begin{array}{l}\mathrm{\Sigma CO}_{2} \\
(\mathrm{~mm})\end{array}$ & $\begin{array}{l}\mathrm{NH}_{4}^{+} \\
(\mathrm{mm})\end{array}$ \\
\hline Loki's Castle & 306 & 6.1 & 395 & 48.7 & 34.8 & 19.6 & 477 & 15.1 & 12.6 & 3.3 & 4.8 & 26.0 & 5.2 \\
\hline Soria Moria & 202 & 4.1 & 319 & 19.6 & 41.1 & 23 & 423 & 10.3 & 0.3 & 4.1 & 0.12 & 91.7 & 0.08 \\
\hline Seawater ${ }^{\mathrm{a}}$ & 1 & 7.9 & 442 & 10.2 & 9.8 & & 545 & & & & & 2.3 & \\
\hline
\end{tabular}

All values were taken from Baumberger (2011) and Pedersen et al. (2010b), except for $\mathrm{O}_{2}$ and $\mathrm{NO}_{3}^{-}$, which were obtained in this study. Concentrations are given in $\mathrm{mmol} \mathrm{kg}{ }^{-1}(\mathrm{~mm})$ or $\mu \mathrm{mol} \mathrm{kg}{ }^{-1}(\mu \mathrm{m})$.

aThe temperature of ambient bottom seawater is $-0.7^{\circ} \mathrm{C}$ at Loki's Castle and $-0.4^{\circ} \mathrm{C}$ at Soria Moria, but was set to $1^{\circ} \mathrm{C}$ in the models. In addition to the listed chemical species, seawater also includes $27.9 \mathrm{~mm} \mathrm{SO}_{4}^{2-}, 405 \mu \mathrm{m} \mathrm{O} \mathrm{O}_{2}$ and $12 \mu \mathrm{m} \mathrm{NO}_{3}^{-}$.

used as template in a five-cycle PCR reaction, using GS FLX Titanium fusion primers. A sample-specific barcode was attached to the forward primer. PCR reactions were run in $25 \mu$ l reactions. PCR product quantification and rinsing of PCR products after the second PCR step was performed as described previously (Roalkvam et al., 2011). The Norwegian High-Throughput Sequencing Centre performed the sequencing using a Roche/454 Life Sciences (Branford, CT, USA) GS-FLX Titanium system.

Filtering, taxonomic analyses and OTU clustering Amplicons where filtered and clustered into operational taxonomic units (OTUs) using Ampliconnoise (Quince et al., 2011). During the filtering step 13$55 \%$ of the reads were filtered out (Supplementary Table 1). OTU clustering was performed with the maximum linkage clustering algorithm and a 3\% difference cutoff.
Taxonomic assignments were performed in CREST (Lanzen et al., 2012), using the last common ancestor algorithm on output from BLASTN (Altschul et al., 1997) searches against the SilvaMod database.

\section{Geochemical modelling}

Similar to a previous study (Amend et al., 2011), the REACT module of the Geochemists Workbench (GWB) software package was used to simulate a stepwise gradual addition of $5000 \mathrm{~kg}$ of SW to $1 \mathrm{~kg}$ of HF. For each small step, the temperature and chemical speciation was evaluated. Minerals were not allowed to precipitate during mixing, redox reactions were prohibited, while acid-base reactions were allowed to reach equilibrium. The GWB analyses used the thermo.com thermodynamic database modified to relevant temperatures and pressures using the subcrt command in Rs CHNOSZ package (Dick, 2008). Subcrt calculates the standard 
Table 2 Overview of environmental samples

\begin{tabular}{|c|c|c|c|c|c|}
\hline Sample name & $\begin{array}{l}\text { Sampling } \\
\text { year }\end{array}$ & Sample description & Vent field & $\begin{array}{l}\text { Technical } \\
\text { replicates }^{\mathrm{a}}\end{array}$ & Reference \\
\hline ROV3 & 2009 & Microbial mat on a chimney wall surface (João) & Loki’s Castle & $a, b$ & Dahle et al. (2013) \\
\hline ROV4 & 2009 & Microbial mat on a chimney wall surface (João) & Loki’s Castle & & Dahle et al. (2013) \\
\hline ROV9 & 2009 & $\begin{array}{l}\text { Microbial mat on a chimney wall surface } \\
\text { (the Camel) }\end{array}$ & Loki's Castle & $\mathrm{a}, \mathrm{b}$ & This study \\
\hline $\mathrm{F} 1, \mathrm{~F} 2, \mathrm{~F} 3, \mathrm{~F} 4$ & 2011 & Four subsamples of a flange structure & Soria Moria & & This study \\
\hline W1 & 2011 & Chimney wall & Soria Moria & $a, b$ & This study \\
\hline
\end{tabular}

${ }^{a}$ In technical replicates, the same DNA extract was analysed by independent $16 \mathrm{~S}$ rRNA gene amplifications and sequencing.
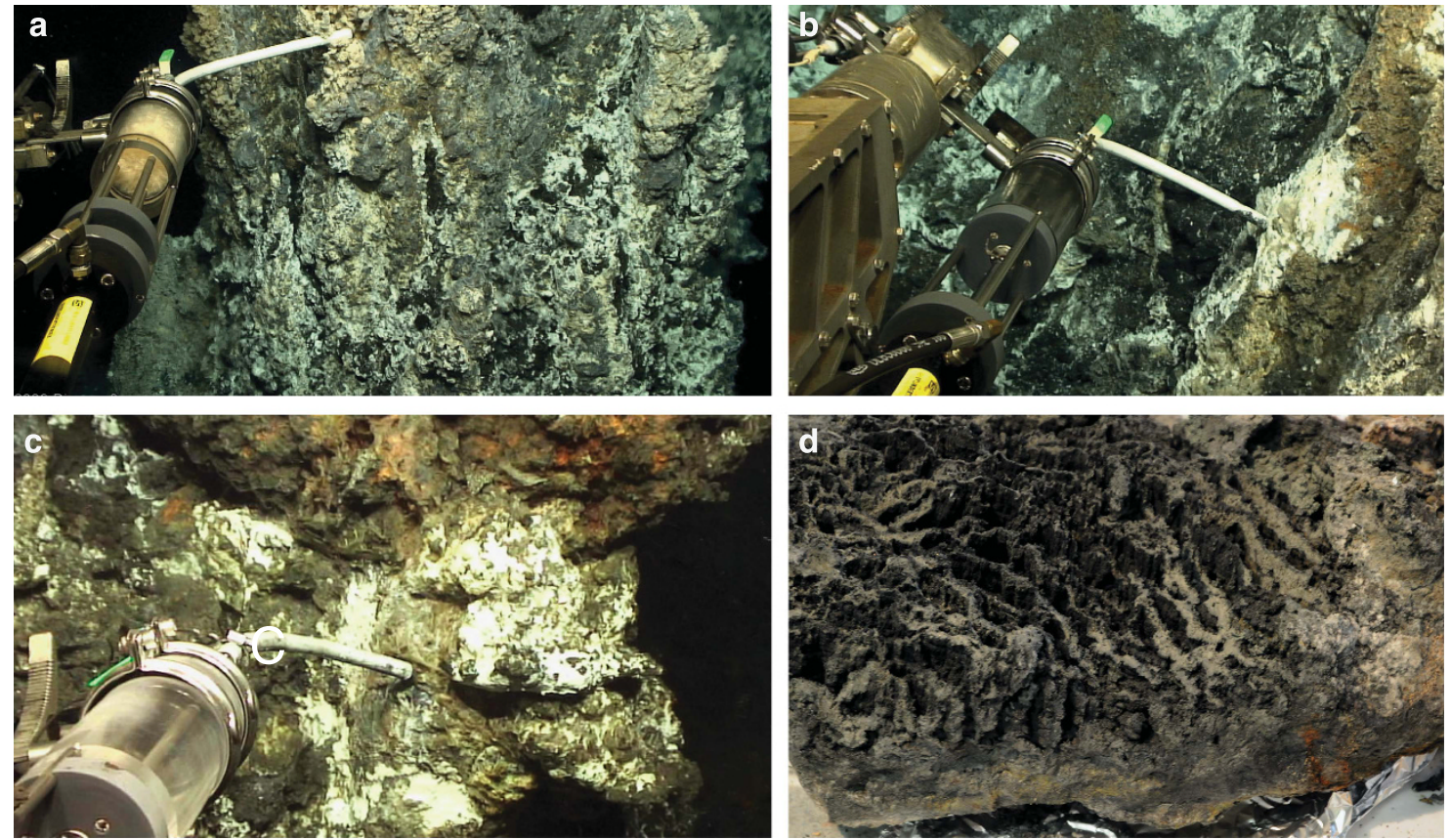

Figure 2 Photographs showing (a) the sampling of ROV3, (b) the sampling of ROV4, (c) the sampling of ROV9 and (d) the flange structure, turned upside down, after arrival on the ship. The samples F1-F4 were subsamples of the flange, whereas the W1 sample was taken in the transition between the flange and the chimney wall.

molal thermodynamic properties of species and reactions as a function of temperature and pressure, and is modelled after the functionality of the SUPCRT92 package (Johnson et al., 1992). Thermodynamic data for ferrihydrite $\left(\mathrm{Fe}(\mathrm{OH})_{3}\right)$ were taken from Majzlan et al. (2004) and Snow et al. (2013). Energy availability per $\mathrm{kg} \mathrm{HF}, E$, from a given redox reaction, $r$, at a given SW:HF mixing ratio was calculated as:

$$
E=\Delta G_{r} L D=\left(\Delta \mathrm{G}_{r}^{0}+R T \ln Q\right) L D
$$

where $\Delta G_{\mathrm{r}}$ is the Gibbs energy of the reaction (in $\mathrm{kJmol}^{-1}$ ), $\Delta G_{\mathrm{r}}^{0}$ is the standard state Gibbs energy (in $\mathrm{kJ} \mathrm{mol}^{-1}$ ) at the relevant temperature and pressure, $T$ is the temperature in Kelvin, $R$ is the gas constant $\left(0.00831 \mathrm{~kJ} \mathrm{~K}^{-1} \mathrm{~mol}^{-1}\right), L$ the number of times (in moles) the reaction can occur per $\mathrm{kg}$ of mixed fluids before the limiting reactant is consumed $\left(\mathrm{mol} \mathrm{kg}^{-1}\right)$ and $D$ is the dilution factor ( $\mathrm{kg}$ of mixed fluids per $\mathrm{kg}$ of $\mathrm{HF}$ ). $\Delta G_{\mathrm{r}}^{0}$ values were calculated using subcrt. The activity product, $Q$, is defined as

$$
Q=\Pi a_{i}^{v_{i}}
$$

where $a_{i}$ is the activity of the ith chemical species and $v_{\mathrm{i}}$ is the stoichiometric reaction coefficient, which is positive for products and negative for reactants. Activities were calculated in GWB using the B-dot equation (Helgeson, 1969).

The temperatures of the calculated mixed solutions were taken to scale linearly with the temperatures of the end members. It has previously been reported that differences in heat capacities between SW and vent fluid only lead to minimal deviation from this linear trend (Amend et al., 2011).

Based on the chemical reactions considered, we defined a set of chemical processes (Table 3). Most processes are defined by a single chemical reaction. Exceptions are aerobic sulphide oxidation, defined by the $\mathrm{H}_{2} \mathrm{~S} / \mathrm{O}_{2}$ and the $\mathrm{HS}^{-} / \mathrm{O}_{2}$ redox pairs, and methanogenesis, defined by the $\mathrm{H}_{2} / \mathrm{CO}_{2}$ and the $\mathrm{H}_{2}$ / $\mathrm{HCO}_{3}^{-}$redox pairs (Table 3). For the energy 
landscape modelling, each chemical process was considered independently. However, different redox reactions that were part of the same process were linked so that the total consumption of the limiting reactant was not allowed to exceed the initial amount. For example, the energy availability from the $\mathrm{HS}^{-} / \mathrm{O}_{2}$ redox pair was dependent on the how much $\mathrm{O}_{2}$ that was remaining after consumption of $\mathrm{O}_{2}$ by the $\mathrm{H}_{2} \mathrm{~S} / \mathrm{O}_{2}$ redox reaction. In effect, the energy available from aerobic sulphide oxidation is defined by the amount of energy released when $\mathrm{HS}^{-}$and $\mathrm{H}_{2} \mathrm{~S}$ in the system reacts with $\mathrm{O}_{2}$ until the limiting reactant (either $\mathrm{O}_{2}$ or $\mathrm{HS}^{-}$and $\mathrm{H}_{2} \mathrm{~S}$ ) is consumed.

\section{Community composition models}

Models of the relative abundance of predefined functional groups of organisms (Table 3) at a given SW:HF mixing ratio were constructed in the form of a Python script (Figure 3). Note that an underlying assumption in these models is that relative reaction rates are dependent on the concentration of the limiting reactants in the system. This becomes evident if we imagine that each loop in the implementation of our model (Figure 3) corresponds to a certain amount of time. In this case, relative reaction rates, defined as the total number of electrons transferred within a given functional group divided by the total number of cycles before the loop ends, will depend directly on relative substrate concentrations. Importantly, in our computer simulation (Figure 3) we let the microbial functional groups acquire energy from redox reactions until all limiting reactants have been consumed. This scenario is probably far from the reality inside or on highly porous chimney walls with a high flux of HFs. However, our models are also applicable to situations where only a fraction of the available energy is used, but then with the assumption that metabolic rates depend on substrate concentrations as indicated above.

\section{Functional assignments and calculation of BCDs}

To directly compare modelled and observed microbial communities, it was necessary to assign metabolic functional groups to the obtained 16S rRNA gene sequences. The assignments were based on the current knowledge about the energy metabolism of close relatives of the detected organisms in addition to the knowledge about the in situ gene expression from metatranscriptomic analyses (Dahle et al., 2013). In effect, all Epsilonproteobacteria as well as Thiotrichales were assigned to sulphide and hydrogen oxidizers, all Methylococcales were assigned to aerobic methane oxidizers and all sequences assigned to the ANME group were assigned to anaerobic methane oxidizers. Sequences assigned to other taxonomic groups were not assigned to any functional group, either because they represented a low abundance of the community or, as for the detected Thaumarchaeota and Crenarchaeota, because of a general lack of knowledge about the metabolic properties of organisms within these taxa. Bray-BCDs between observed and modelled communities were calculated in VEGAN v. 1.17-6 (Oksanen et al., 2011).

\section{Deposition of sequence data}

Raw sequence data have been submitted to the Sequence Read Archive under the accession numbers SRP040005 (ROV9, F1-4 and W1) and SRP011918 (ROV3 and ROV4).

Table 3 Overview of chemical processes and defined functional groups of microorganism

\begin{tabular}{|c|c|c|c|}
\hline Functional group & Process & Redox reaction(s) & $\begin{array}{l}\text { Reaction } \\
\text { number }\end{array}$ \\
\hline \multirow{6}{*}{$\begin{array}{l}\text { Sulphur and hydrogen } \\
\text { oxidizers }\end{array}$} & Sulphide oxidation with oxygen & $\mathrm{H}_{2} \mathrm{~S}+2 \mathrm{O}_{2} \rightarrow \mathrm{HSO}_{4}^{-}+\mathrm{H}^{+}$ & 1a \\
\hline & \multirow{3}{*}{ Sulphide oxidation with nitrate } & $\mathrm{HS}^{-}+2 \mathrm{O}_{2} \rightarrow \mathrm{HSO}_{4}^{-}$ & $1 \mathrm{~b}$ \\
\hline & & $\begin{array}{l}5 \mathrm{H}_{2} \mathrm{~S}+8 \mathrm{NO}_{3}^{-} \rightarrow 5 \mathrm{HSO}_{4}^{-}+\mathrm{H}_{2} \mathrm{O}+4 \mathrm{~N}_{2}+ \\
3 \mathrm{OH}^{-}\end{array}$ & $\begin{array}{l}2 \mathrm{a} \\
2 \mathrm{~b}\end{array}$ \\
\hline & & $\begin{array}{l}5 \mathrm{HS}^{-}+4 \mathrm{H}_{2} \mathrm{O}+8 \mathrm{NO}_{3}^{-} \rightarrow \\
5 \mathrm{HSO}_{4}^{-}+4 \mathrm{~N}_{2}+8 \mathrm{OH}^{-}\end{array}$ & \\
\hline & Hydrogen oxidation with oxygen & $2 \mathrm{H}_{2}+\mathrm{O}_{2} \rightarrow 2 \mathrm{H}_{2} \mathrm{O}$ & 3 \\
\hline & Hydrogen oxidation with nitrate & $5 \mathrm{H}_{2}+2 \mathrm{NO}_{3}^{-}+2 \mathrm{H}^{+} \rightarrow \mathrm{N}_{2}+6 \mathrm{H}_{2} \mathrm{O}$ & 4 \\
\hline Methane oxidizers & Methane oxidation (aerobic) & $\mathrm{CH}_{4}+2 \mathrm{O}_{2} \rightarrow \mathrm{CO}_{2}+2 \mathrm{H}_{2} \mathrm{O}$ & 5 \\
\hline Ammonium oxidizers & Ammonium oxidation & $\mathrm{NH}_{4}^{+}+2 \mathrm{O}_{2} \rightarrow \mathrm{NO}_{3}^{-}+\mathrm{H}_{2} \mathrm{O}+2 \mathrm{H}^{+}$ & 6 \\
\hline Iron oxidizers & Iron oxidation & $4 \mathrm{Fe}^{2+}+\mathrm{O}_{2}+10 \mathrm{H}_{2} \mathrm{O} \rightarrow 4 \mathrm{Fe}(\mathrm{OH})_{3}+8 \mathrm{H}^{+}$ & 7 \\
\hline \multirow[t]{2}{*}{ Anaerobic methane oxidizers } & $\begin{array}{l}\text { Methane oxidation (anaerobic with } \\
\text { sulphate) }\end{array}$ & $\mathrm{CH}_{4}+\mathrm{SO}_{4}^{2-}+2 \mathrm{H}^{+} \rightarrow \mathrm{CO}_{2}+\mathrm{H}_{2} \mathrm{~S}+2 \mathrm{H}_{2} \mathrm{O}$ & 8 \\
\hline & $\begin{array}{l}\text { Methane oxidation (anaerobic with } \\
\text { nitrate) }\end{array}$ & $\mathrm{CH}_{4}+4 \mathrm{NO}_{3}^{-} \rightarrow \mathrm{CO}_{2}+4 \mathrm{NO}_{2}^{-}+2 \mathrm{H}_{2} \mathrm{O}$ & 9 \\
\hline \multirow[t]{2}{*}{ Methanogens } & Methanogenesis & $4 \mathrm{H}_{2}+\mathrm{CO}_{2} \rightarrow \mathrm{CH}_{4}+2 \mathrm{H}_{2} \mathrm{O}$ & $10 \mathrm{a}$ \\
\hline & & $4 \mathrm{H}_{2}+\mathrm{HCO}_{3}^{-}+\mathrm{H}^{+} \rightarrow \mathrm{CH}_{4}+3 \mathrm{H}_{2} \mathrm{O}$ & $10 \mathrm{~b}$ \\
\hline Sulphate reducers & Sulphate reduction & $4 \mathrm{H}_{2}+\mathrm{SO}_{4}^{2-}+2 \mathrm{H}^{+} \rightarrow \mathrm{H}_{2} \mathrm{~S}+4 \mathrm{H}_{2} \mathrm{O}$ & 11 \\
\hline
\end{tabular}

Compounds in the redox reactions are in the aqueous phase, except for $\mathrm{Fe}(\mathrm{OH})_{3}$, which represents the mineral ferrihydrite.

${ }^{a}$ This reaction was included in the definition of anaerobic methane oxidizers only when specified. 


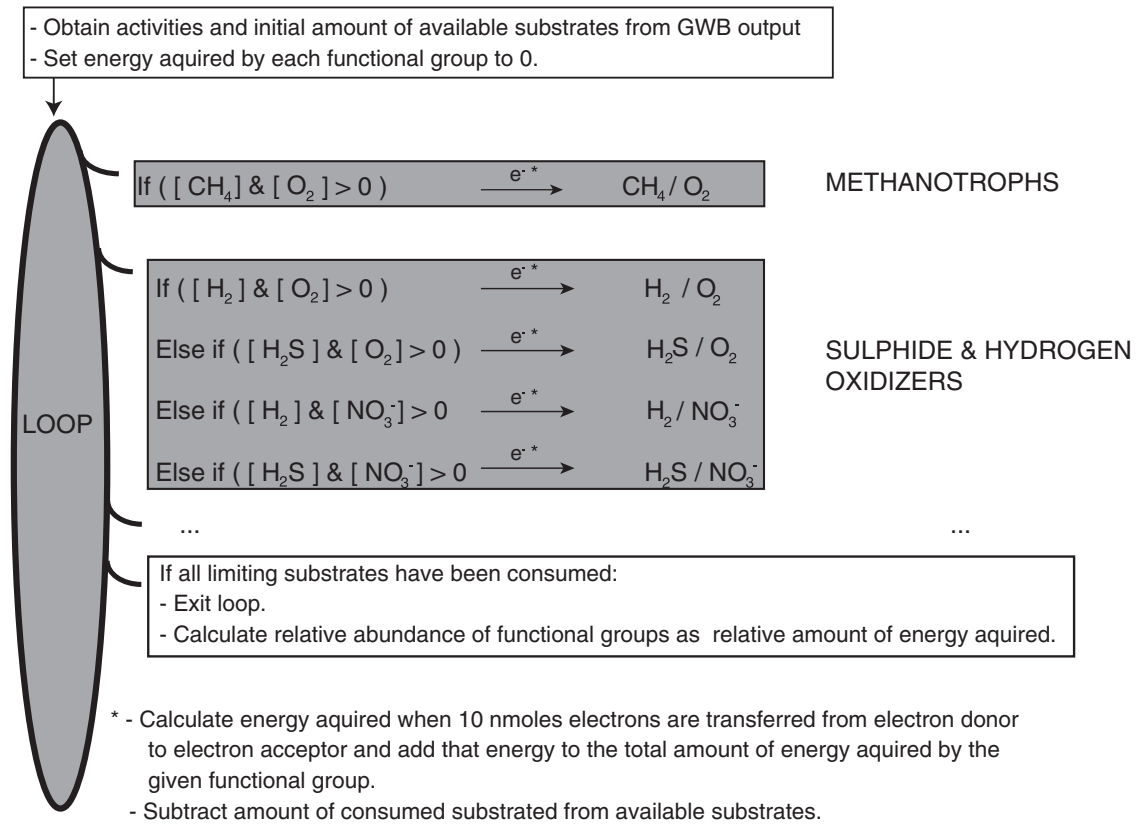

Figure 3 Illustration of the implementation of community composition models in a computer script. For clarity, only two functional groups are shown. First, activities and total amounts of each substrate were extracted from the GWB output. In some cases (specified in the results section), the amounts of oxygen and hydrogen sulphide were decreased stoichiometrically (2:1, see Table 3) at this step to simulate the effect of abiotic sulphide oxidation. Second, a loop was initiated where for each iteration each functional microbial group was allowed to acquire energy by the transfer of $10 \mathrm{nmol}$ of electrons in a redox reaction within the definition of that group. The consumption of each reactant was then calculated and subtracted from the amount of substrate available. A given redox reaction was allowed to be used as an energy source only as long as none of the substrates had been fully consumed. For functional microbial groups able to use multiple redox reactions (such as sulphide and hydrogen oxidizers), the most exergonic reaction was selected at each step. The loop was continued until none of the redox reactions were allowed to proceed owing to substrate limitations. Finally, the relative abundance of each functional microbial group was calculated as the relative amount of energy acquired by that group. Note that the community composition models take into account that the redox reactions considered are not independent as some reactants occur in several reactions. Hence, different functional groups may compete for some of the same substrates (e.g. all aerobic organisms compete for oxygen).

\section{Results}

Energy landscapes at LCVF and SMVF

Gibbs energies from 10 chemical reactions or processes (Table 3) were modelled at different SW:HF mixing ratios at SMVF and LCVF. Our models consider maximum potential energies per $\mathrm{kg}$ of HF (Figure 4). Negative values of Gibbs energy indicate exergonic reactions acting as potential energy sources for microorganisms.

Note that the individual reactions considered in Figure 4 are not independent in the sense that they share some of the same reactants. Thus, the reported total energy yields for each reaction cannot be achieved simultaneously from the same volume of fluids. Also note that changes in energy availability are not primarily due to variations in temperature, but that both temperatures and total energy availabilities vary as a consequence of different SW:HF mixing ratios.

Energy landscapes varied largely between the two fields. At low temperatures, sulphide oxidation was the dominant energy source at SMVF (up to $3.3 \mathrm{~kJ} \mathrm{~kg}^{-1} \mathrm{HF}$ ) (Figure 4). The energy availability from this reaction decreased at increasing temperatures, but remained the dominant energy source, together with aerobic methane oxidation, at temperatures above $70^{\circ} \mathrm{C}$. At LCVF aerobic methane oxidation was dominant at low temperatures (up to $10.6 \mathrm{~kJ} \mathrm{~kg}^{-1} \mathrm{HF}$ ) (Figure 4b). Aerobic sulphide and methane oxidation were approximately equally exergonic at temperatures above $17^{\circ} \mathrm{C}$. At around $33^{\circ} \mathrm{C}$ aerobic methane oxidation, sulphide and hydrogen oxidation and anaerobic methane oxidation were approximately equally exergonic, but at higher temperatures anaerobic methane oxidation was clearly the most dominant energy source (up to $1.3 \mathrm{~kJ} \mathrm{~kg}^{-1} \mathrm{HF}$ ). In addition to aerobic and anaerobic methane oxidation, ammonium oxidation and hydrogen oxidation were considerably more exergonic at LCVF than at SMVF. Owing to the relatively low concentration of $\mathrm{NO}_{3}^{-}$in $\mathrm{SW}$ (compared with $\mathrm{O}_{2}$ and $\mathrm{SO}_{4}^{2-}$ ), energy availabilities from nitrate reduction were substantial only at very high SW:HF mixing ratios. Energy availabilities in reactions involving $\mathrm{O}_{2}$ or $\mathrm{NO}_{3}^{-}$as the electron acceptor reached a plateau at high SW:HF mixing ratios. These plateaus occur at mixing ratios where the electron acceptor is no longer limiting (not shown).

\section{Microbial community models}

Community compositions were predicted from models using slightly different assumptions 
Soria Moria

SW:HF mixing ratio

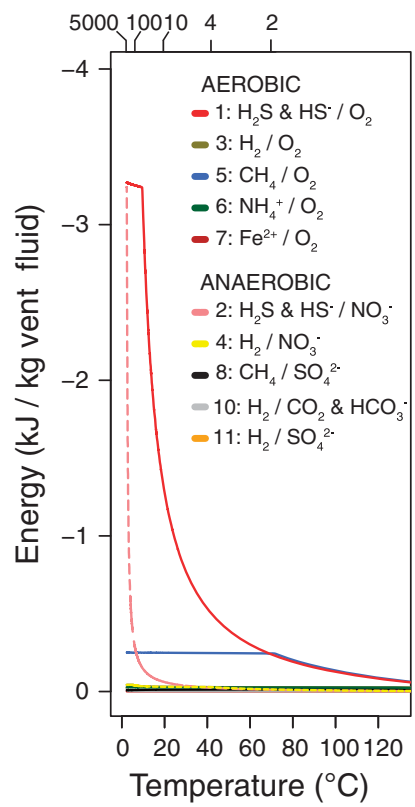

Loki's Castle

SW:HF mixing ratio

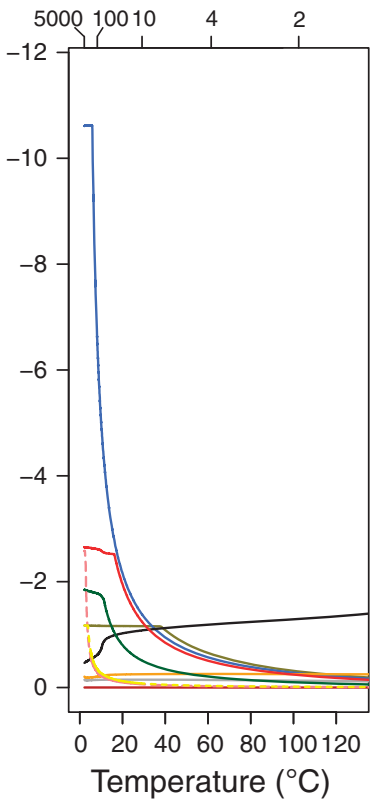

Figure 4 Modelled energy availability from 10 redox processes (see Table 3) as a function of temperature and SW:HF mixing ratios at the SMVF and the LCVF. Second axis indicates the energy released when reactants in a mixture of SW and $1 \mathrm{~kg}$ hydrothermal fluid react until equilibrium is reached. Numbers in the legend refer to numbered redox reations in Table 3. For clarity, energies from redox reactions with nitrate as the electron acceptor are indicated with dashed lines. Note that different redox processes are considered independently.

(Figure 5). In models assuming no abiotic reactions, aerobic methane oxidizers together with hydrogen and sulphide oxidizers were predicted to dominate at all temperatures considered at SMVF (Figure 5a). Ammonium oxidizers increased in abundance at increasing temperatures up to $95^{\circ} \mathrm{C}$, where the abundance reached a maximum of $15 \%$. Community composition predictions from SMVF were highly sensitive to the introduction of abiotic oxygen reduction as a model assumption. When up to $10 \%$ of sulphide was allowed to react with oxygen abiotically, the communities were predicted to shift at around $60-80^{\circ} \mathrm{C}$ from a dominance of sulphide and hydrogen oxidizers as well as methane oxidizers at low temperatures to anaerobic methane oxidizers at high temperatures (Figure 5c). This shift was even more apparent when we, in addition to the abiotic sulphide oxidation, allowed anaerobic methane oxidizers to acquire energy from nitrate reduction (Figure 5).

In the community composition models from LCVF, the distribution of microbial functional groups were predicted to vary considerably at different SW:HF mixing ratios and corresponding temperatures (Figure 5b). At low temperatures $\left(<8^{\circ} \mathrm{C}\right)$, aerobic methane oxidizers were predicted to dominate with relative abundances of up to $49 \%$ of the community. Sulphide and hydrogen oxidizers (up to $37 \%$ ) and ammonium oxidizers (up to $20 \%$ ) were also predicted to be abundant. At higher temperatures, the abundances of these groups decreased continuously, and at around $20^{\circ} \mathrm{C}$, aerobic methane oxidizers, anaerobic methane oxidizers and sulphide/hydrogen oxidizers had an approximately equal abundance of $29-30 \%$. At temperatures above $20^{\circ} \mathrm{C}$, anaerobic methane oxidizers were predicted to become increasingly dominant, with relative abundances of up to $82 \%$. Also, methanogens and sulphate reducers increased in abundance at increasing temperatures, but their relative abundances never exceeded $7 \%$.

Predicted communities at LCVF at moderate to high temperatures were dominated by anaerobes (Figure $5 \mathrm{~b}$ ) and the communities were therefore overall not very sensitive to oxygen removal by abiotic oxygen reduction (Figure $5 \mathrm{~d}$ ). Differences in assumptions regarding the metabolic capabilities of anaerobic methane oxidation also had a minor effect (Figure 5f). However, note that abiotic sulphide oxidation had a large effect on relative abundances of anaerobic sulphate reducers and methanogens compared with aerobic groups at temperatures above $60{ }^{\circ} \mathrm{C}$ (Figures 5b, d and f).

\section{Case studies}

Temperature measurements inside or near the ROV3, ROV4 and ROV9 biofilms at LCVF fluctuated between ambient SW temperature $\left(-0.7^{\circ} \mathrm{C}\right)$ and $40^{\circ} \mathrm{C}$. Accurate in situ temperatures at the sampling points could not be obtained owing to difficulties with keeping the ROV in a fixed position. Temperature measurements under the SMVF flange were stable in the range of $70-72{ }^{\circ} \mathrm{C}$.

Epsilonproteobacteria dominated in the ROV3 and ROV4 samples (Figure 6). The three most dominant Epsilonproteobacteria OTUs from ROV3, representing 94\% of the Epsilonproteobacteria in this sample, were similar (94-95\%) to Sulfurovum lithotrophicum (accession number AB091292). The three most dominant Epsilonproteobacteria OTUs from ROV4, representing 65\% of the Epsilonproteobacteria, were similar (95-100\%) to Sulfurimonas denitrificans (accession number L40808) or Sulfurimonas autotrophica (accession number AB088431). Cultured members of Epsilonproteobacteria detected in hydrothermal systems are microaerophilic sulphur oxidizers with a versatile metabolism including the ability to use various sulphur compounds and hydrogen as electron donors, and oxygen and nitrate as the electron acceptor (Campbell et al., 2006). Gammaproteobacteria of the Methylococcales order dominated in ROV9 (Figure 6 and Supplementary Figure 1). Within this group, $87 \%$ of the sequences clustered in an OTU that was $100 \%$ similar to endosymbiotic methane oxidizers from the Logachev vent field (accession 

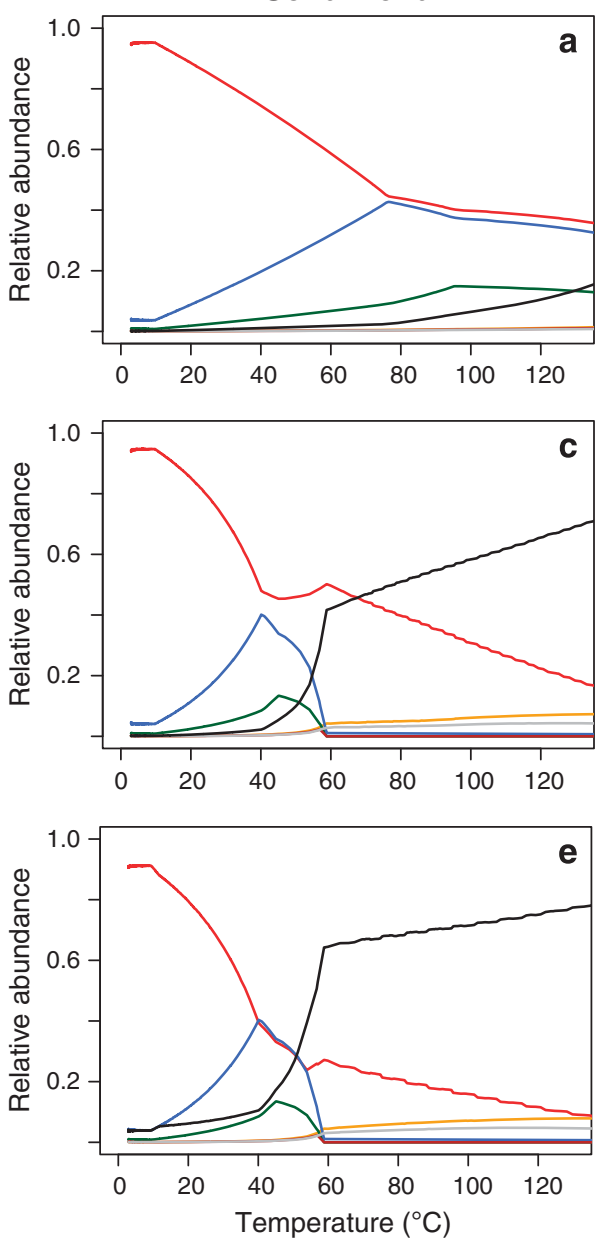

Loki's Castle
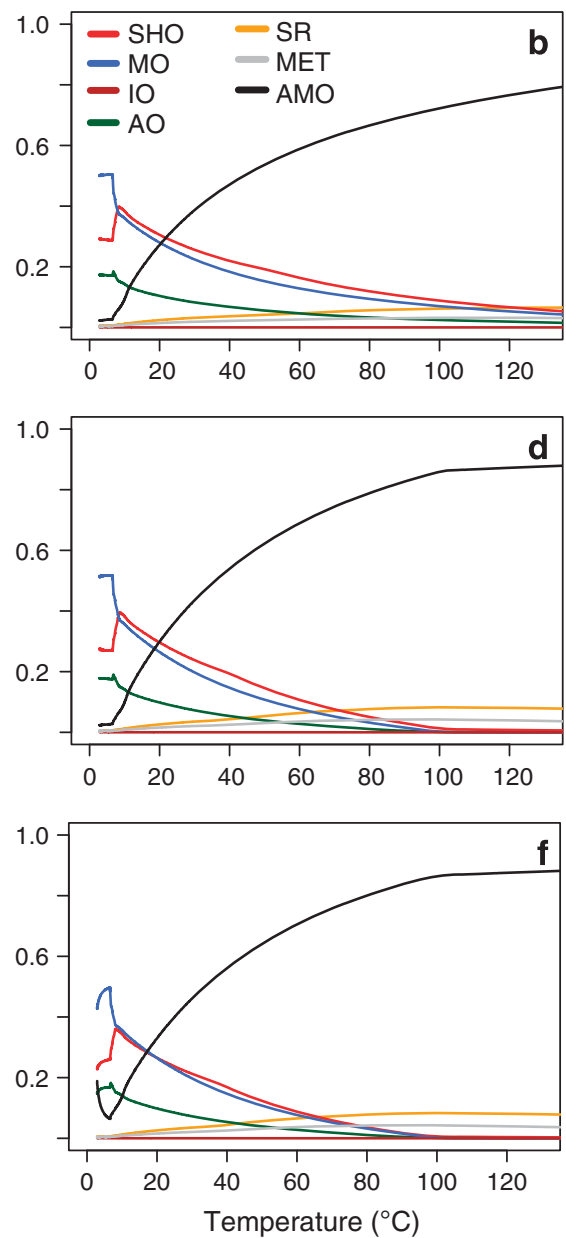

Figure 5 Predicted relative abundances of seven functional groups of microorganisms (defined in Table 3) as a function of temperature and SW:HF mixing ratios at the SMVF and the LCVF. (a and b) Predicted relative abundances from models assuming that no abiotic reactions take place. (c and d) Predicted relative abundances from models assuming that up to $10 \%$ of the sulphide reacts abiotically with oxygen. (e and f) Predicted relative abundances from models assuming that up to $10 \%$ of the sulphide reacts abiotically with oxygen and that anaerobic methane oxidizers have the ability to use nitrate in addition to sulphate as the electron acceptor. AMO, methane oxidizers (anaerobic); AO, ammonium oxidizers; MET, methanogens; MO, methane oxidizers (aerobic); IO, iron oxidizers; SHO, sulphide and hydrogen oxidizers; SR, sulphate reducers.

number AM083965) (Duperron et al., 2006), whereas $12 \%$ clustered in a OTU that was $96 \%$ similar to the methanotrophic Methylomarinum vadi (accession number AB301717) (Hirayama et al., 2013). Epsilonproteobacteria were also detected here with an abundance of 9-11\% (Figure 6), and members of this group were similar to the ROV3 and ROV4 samples, mostly assigned to the Sulfurovum and Sulfurimonas genera (Supplementary Figure 1).

Crenarchaeota from the MCG clade or Euryarchaeota from the ANME-1 clade dominated in the SMVF flange (samples F1-F4) (Figure 6 and Supplementary Figure 1). Dominant Methanomicrobia and MCG OTUs from the F1-F4 samples were closely related to organisms detected in hydrothermally active environments or in thermophilic enrichments. For example, the closest relatives (98-99\% similarity) of the most dominant ANME OTU, representing $91 \%$ of all Methanomicrobia detected in the flange, were found in $50{ }^{\circ} \mathrm{C}$ enrichments inoculated with hydrothermal sediments from the Guaymas Basin (accession number FR682489) (Holler et al., 2011), hypothesized thermophilic ANME (accession number AF419624) (Teske et al., 2002) and ANME detected in an oil reservoir with an in situ temperature of $75^{\circ} \mathrm{C}$ (accession number DQ857984) (Li et al., 2007). The closest relatives (99\% similarity) of the most abundant MCG OTU from F1 to F4, representing 17\% of all MCG in these samples, were detected in hydrothermal sediments at the Southern Mariana Through (accession number AB213057) (Kato et al., 2009).

The W1 sample was dominated by MCG, but we also detected high abundances of Thaumarchaeotal group 1A, Thaumarchaeotal Terrestrial hot spring group and some Aquificaceae (Figure 5). The two most dominant MCG OTUs from the W1 sample, representing $69 \%$ of all MCG in this sample, were most similar (95-99\%) to organisms detected in hydrothermal sediments at the Southern Mariana 
Trough (accession numbers AB213100 and AB213101) (Kato et al., 2009). The most dominant Aquificaceae OTU in the F1-F4 and W1 samples, representing $84.3 \%$ of Aquificaceae in $\mathrm{F} 1-\mathrm{F} 4$ and $95.9 \%$ of Aquificaceae in W1, was $93 \%$ similar to the thermophilic hydrogen oxidizing Persephonella marina (accession number NR_027538) (Gotz et al., 2002).

\section{BCDs between modelled and observed communities}

To compare modelled and observed communities, we assigned metabolic functions to detected organisms based on information about their closest relatives (Figure 7). We then measured BCDs in community composition between observed and predicted communities. The F2, F3 and W1 samples were excluded from these analyses owing to their high content of uncultured groups of Thaumarchaeota and Crenarchaeota, with largely unknown metabolic capabilities (Figure 7). The ROV3, ROV4 and ROV9 biofilms were most similar to predicted communities at low temperatures (Figure 8), which

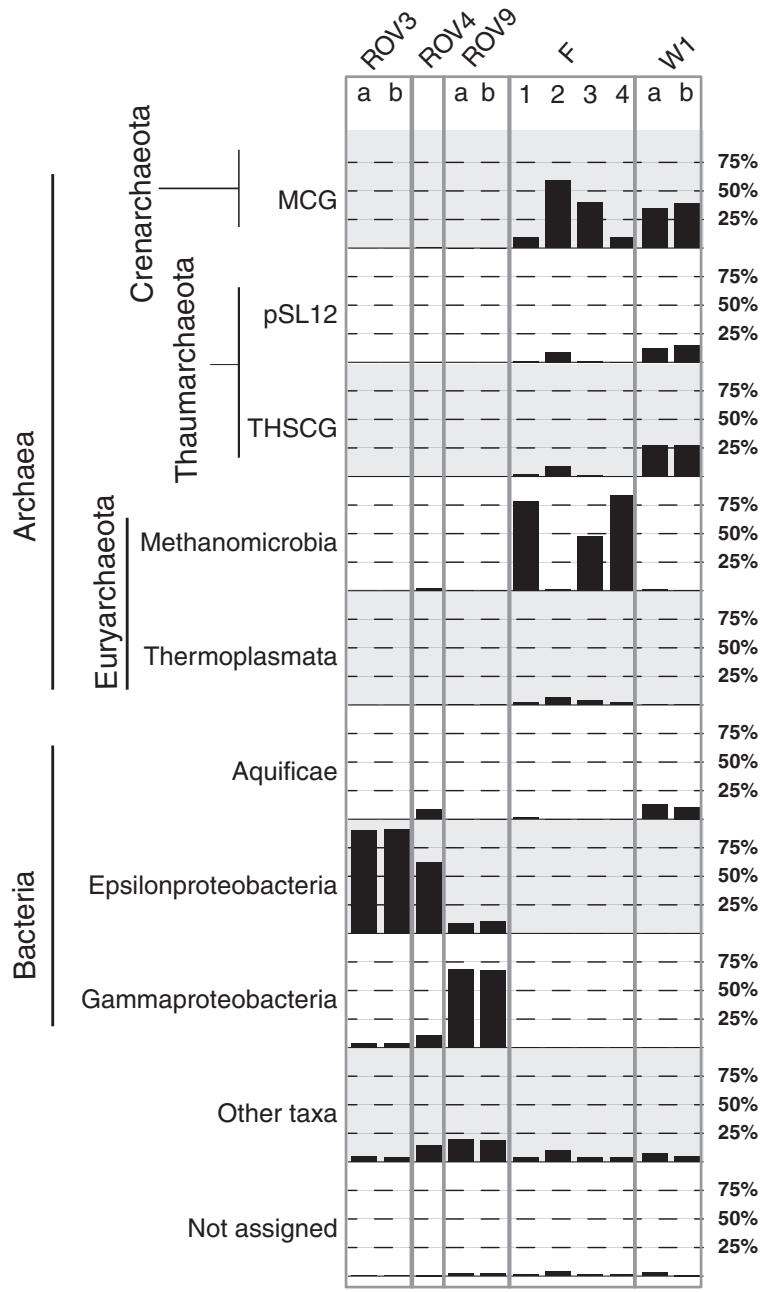

Figure 6 Phylum- to class-level taxonomic assignments of $16 \mathrm{~S}$ rRNA gene reads obtained from LCVF biofilms (ROV3, ROV4, ROV9), and flange and chimney samples from the SMVF (F1-4 and W1). Replicates are indicated with letters 'a' and 'b'. is consistent with their appearance on the chimney surface at presumably high SW:HF mixing ratios. The flange samples (F1 and F4) fit poorly with community predictions unless we assumed that up to $10 \%$ of the sulphide was allowed to react with oxygen abiotically. In the latter case, the BCD decreased from nearly 1 at low temperatures to below 0.4 under thermophilic conditions. Interestingly, an even better fit was obtained when anaerobic methane oxidizers were allowed to reduce nitrate in the community composition models (Figure 8). The better fit at high temperatures is consistent with the measured in situ temperature $\left(71-72{ }^{\circ} \mathrm{C}\right)$. Note that the community compositions in F1 and F4 are highly similar. For clarity, only F1 is included in Figure 8.

\section{Discussion}

In this study, we developed, for the first time, microbial community composition models that are based on modelled energy landscapes. Through comparisons between observed and modelled communities, we provide evidence that the distribution of functional groups within chemotropic microbial communities is largely determined by chemical energy availability. Our results also indicate that a sedimentary influence in the host rocks can have a large impact on energy landscapes, and hence microbial communities, in hydrothermal systems. Finally, we demonstrate some of the sensitivity of the community composition predictions to assumptions regarding geochemical processes and metabolic capabilities.

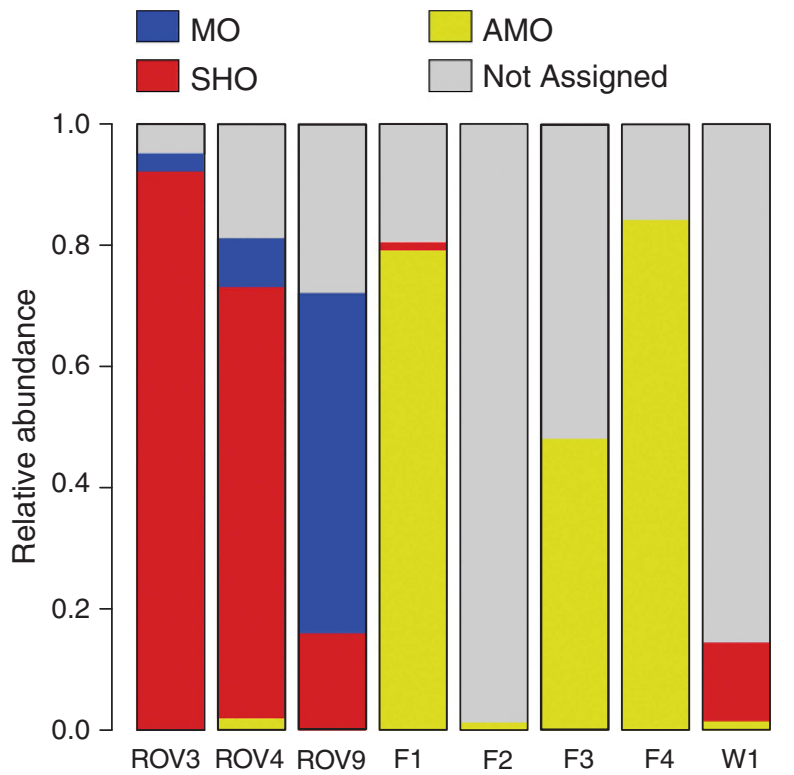

Figure 7 Functional community compositions of the analysed samples as assessed by $16 \mathrm{~S}$ rRNA gene sequence information. AMO, anaerobic methane oxidizers (anaerobic); MO, methane oxidizers (aerobic); SHO, sulphide and hydrogen oxidizers. 
1602

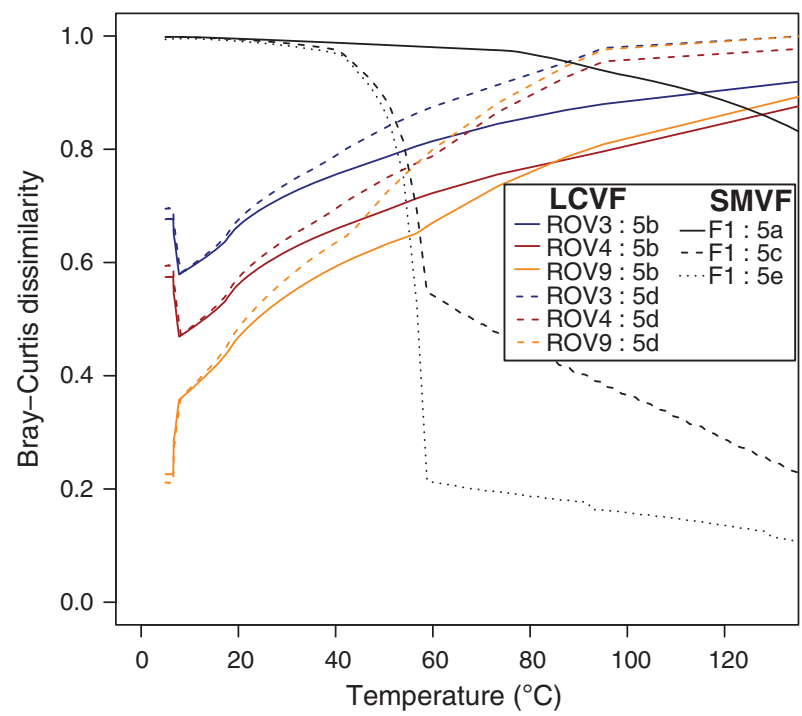

Figure 8 BCDs between microbial community compositions assessed from observed 16S rRNA gene sequences (Figure 7) and modelled communities. As indicated, each line shows BCD values from comparisons between one sample and communities shown in one of the subfigures of Figure 5. For example, blue solid lines show BCD values from comparisons between ROV3 and predicted communities for different temperatures at LCVF as shown in Figure 5b. All solid lines involve comparisons with predictions based on the assumption that no abiotic sulphide oxidation takes place. Dashed lines involve comparisons with predictions based on models assuming that up to $10 \%$ of the sulphide reacts with oxygen abiotically. The dotted line shows comparisons between F1 and predicted communities that were based on a model where anaerobic methane oxidizers can use nitrate as the electron acceptor in addition to sulphate. Also in this case the model assumes that up to $10 \%$ of the sulphide reacts with oxygen abiotically. BCD can take values between 0 and 1 , where high values indicate low similarities between observed and modelled communities. Note that BCD involving F1 and F4 samples gave highly similar results and that only $\mathrm{F} 1$ is plotted for clarity.

Energy landscapes (Figure 4) were modelled using a similar approach as in a recent study that compared energy landscapes in hydrothermal systems at different geological settings (Amend et al., 2011), including the basalt-hosted Endeavour field, which is inferred to be sediment influenced based on elevated methane and ammonium concentrations (Lilley et al., 1993). However, energy availability from aerobic methane oxidation in the systems investigated by Amend et al. (2011) never exceeded $4 \mathrm{kJl}^{-1} \mathrm{HF}$ at $1 \% \mathrm{HF}: \mathrm{SW}$ mixing ratios, which is only one-third of the maximum energy availability from this reaction at LCVF (Figure 4b). In all of the systems investigated by Amend et al. (2011), anaerobic methane oxidation was found to be anemic or minimally exergonic at 1 and $10 \% \mathrm{HF}$ contribution in SW:HF mixtures, which is in sharp contrast to high energy availabilities from this process above $20^{\circ} \mathrm{C}$ at LCVF. Amend et al. (2011) did not calculate energy availability from ammonium oxidation, but it should be noted that among all vent fields investigated, the Endeavour field had the highest endmember ammonium concentration
(0.503 mм) (Seewald et al., 2003; Seyfried et al., 2003), which is only about one-tenth of the concentration observed at LCVF (Table 1). Taken together, this suggests that the sediment-influenced LCVF represents an extremity regarding the energetic potential for hosting anaerobic and aerobic methane oxidizers, as well as aerobic ammonium oxidizers.

Sluggish reaction rates of abiotic methane oxidation, sulphide oxidation, iron oxidation and sulphate reduction have been observed under conditions relevant for deep-sea hydrothermal systems (Kadko et al., 1990; Shock and Holland, 2004; Houghton and Seyfried, 2010; Foustoukos et al., 2011). Hence, the assumption that modelled energy landscapes reflect relevant energy availabilities for microbial communities seems justified. Remarkably, it was recently argued that energy density (energy availability per volume) is a far better indicator of biomass in sediment cores than the energy available per mole of reaction or per mole of electrons transferred from the electron donor to the electron acceptor (LaRowe and Amend, 2014). This lends confidence to our community composition predictions, which are based on modelled energy densities.

The microbial community compositions were predicted under slightly different assumptions: with or without some abiotic sulphide oxidation or letting anaerobic methane oxidizers have or not have the ability to reduced nitrate in addition to sulphate. Under the conditions in the SMVF flange (with an in situ temperature of $72^{\circ} \mathrm{C}$ ), models not allowing abiotic reactions predict that there is enough oxygen for aerobic organisms to dominate from $0-130^{\circ} \mathrm{C}$ (Figure 5a). However, the dominance of putative strictly anaerobic methane oxidizers in the flange indicates anaerobic conditions. Furthermore, the absence or very low abundance of putative aerobic organisms in the flange samples indicates that any oxygen removal is not biogenic. Hence, the assumption that oxygen is reduced abiotically seems justified in this case. In line with this, fluids can be expected to flow relatively slowly through the pores in the flange, potentially giving enough time for reducing agents (e.g. sulphide) to react with oxygen, thereby providing conditions that favour the anaerobic methane oxidizers, as predicted by our models (Figures 5c and e). Higher flow rates and less abiotic sulphide oxidation could be expected in the chimney wall. Interestingly, the predicted higher abundance of hydrogen and sulphide oxidizers under such conditions (Figure 5a) is consistent with the low abundance of ANME and an elevated abundance of putatively microaerobic and thermophilic sulphide oxidizers of the Aquificaceae family in the W1 sample.

It was recently shown that some ANME are able to grow by reduction of nitrate to nitrite combined with reverse methanogenesis (Haroon et al., 2013). We have no strong support for assuming that the ANME detected in the SMVF flange can grow by 
denitrification, but it is interesting to note that models using this assumption provides the community composition predictions that are mostly consistent with the observed communities (Figure 8).

We have not included thermal conduction in our models, which would have had the effect that each temperature would have consistently been associated with a lower SW:HF mixing ratio than in the current models. Hence, as seen in Figure 5 and Figure 8, assuming heat transfer by thermal conduction in the SMVF flange may have resulted in predictions that are highly consistent with the observed dominance of ANME even when ANME are assumed to be obligate sulphate reducers.

Organic compounds (other than methane) are available to organotrophic organisms from primary production, and may also be present in the venting fluids at LCVF and JMVF. Organotrophic organisms were therefore expected to be present in these systems. Indeed, putative organontrophic Bacteroidetes and potentially organotrophic Chloroflexi were present in the ROV3, ROV4 and ROV9 mats with relative abundances of up to $4.2 \%$ (Bacteroidetes) and $6.2 \%$ (Chloroflexi) (Supplementary Figure 1), suggesting some energy transfer from primary producers to microbial organotrophic consumers in these habitats. Some putative organotrophic and thermophilic Thermotogales and Thermococcales were also detected $(<0.7 \%)$ (Supplementary Figure 1), indicating that these organisms are important organotrophic consumers in the chimney wall. It could also be that some of the Crenarchaeota or Thaumarchaeota detected in the flange and chimney wall at SMVF (Figure 6) are organotrophs. Some Epsilonproteobacteria may also grow organotrophically (e.g. on formate), which partly could explain the high abundance of Epsilonproteobacteria at LCVF. Yet, a high gene expression of genes involved in hydrogen oxidation, sulfide oxidation and carbon fixation by these Epsilonproteobacteria is suggestive of a lithoautotrophic lifestyle (Dahle et al., 2013). However, owing to our lack of knowledge regarding organic compounds in the venting fluids and as considering entire food webs was beyond the scope of our study, organotrophic organisms were not included in the community composition models. Hence, the predicted communities should be regarded as predicted distributions of lithoautrotrophic and methanotrophic organisms only. Future studies, more directed towards assessing energy landscapes relevant for organotrophic organisms in combination with analyses of more environmental samples, may clarify the energy flow from autotrophic primary producers to heterotrophic consumers in hydrothermal systems.

A detailed investigation of the extent to which energy availability shape microbial communities is difficult without a detailed knowledge about the geochemical processes that influence the energy landscapes and the metabolic capabilities of the organisms using the available energy sources. Nevertheless, our models seem, to a large extent, to correctly predict which functional groups of organisms dominate under different energy landscapes: consistent with the predicted community compositions, putative mesophilic sulphide and hydrogen oxidizers, as well as methane oxidizers, dominate on chimney surfaces at LCVF, whereas ANME dominate in the SMVF flange. This predictive power is further illustrated in Figure 8, which shows that by only assessing energy landscapes and the distribution of functional groups in our samples, we could have correctly predicted if the samples were associated with low or high SW:HF mixing ratios (or high or low temperatures). This indicates that, at least on a broad level, there is a close connection between energy availability and microbial community composition.

The discrepancies between predicted and observed communities are also interesting. In the predicted community composition for LCVF, ammonium oxidizers reached abundances of up to $20 \%$ at high SW:HF mixing ratios. Yet, none of the organisms detected in the LCVF samples seem to be affiliated to this metabolic group. Possibly, ammonium oxidizers are outcompeted by organisms using more exergonic redox reactions on the chimney surface, such as methane and sulphide oxidation. Similarly, anaerobic methane oxidizers may outcompete sulphide and hydrogen oxidizers at high temperatures in SMVF. Given the high energy availability from ammonium oxidation at LCVF, elevated abundances of ammonium oxidizers can be expected to be present in the hydrothermal plume forming in the water column above this vent field. Interestingly, elevated ammonium concentrations and ammonium oxidation rates have been observed in other hydrothermal plumes (Lam et al., 2008)

Members of MCG have been detected in a variety of habitats including hot springs, marine sediments and mud volcanoes (Barns et al., 1996; Parkes et al., 2005; Heijs et al., 2007; Kubo et al., 2012). Typically, ANME have been detected in marine methane seeps or hydrothermal sediments, but have also been inferred to be present in low-temperature exterior parts of flange samples from the Lost City hydrothermal field (Brazelton et al., 2006). Yet, to our knowledge, this is the first report of the presence of ANME and MCG in flange interiors. Recently, members of ANME were detected in thermophilic enrichments using hydrothermally influenced sediments as inoculum (Holler et al., 2011), whereas putatively thermophilic ANME were detected in diffuse hydrothermal vent fluids (Merkel et al., 2013). No direct evidence for the existence of thermophilic MCG have so far been obtained. Based on three observations, we infer that ANME and MCG in the SMVF flange are thermophiles: (i) owing to the high porosity of the lower part of the flange where the samples were taken, it seems unlikely that the in situ temperature at the sampling sites were 
much different than the in situ temperature measured directly under the flange $\left(>70^{\circ} \mathrm{C}\right)$. (ii) Dominating OTUs within MCG and ANME-1 are close relatives of organisms detected in hydrothermal or thermophilic enrichments. (iii) MCG and ANME co-occurred with members of thermophilic groups such as Aquificacea, Thermodesulfobacteria, Archaeoglobi and the Terrestrial Hot Spring Group (Figure 5; Supplementary Figure 1).

\section{Concluding remarks}

Although we analysed a limited number of samples and the energy metabolism of some of the detected microbial groups was not always clear, the high degree of consistency between community compositions assessed by 16S rRNA gene sequences and predicted community compositions indicates that energy availability to a large extent shape microbial communities in hydrothermal systems. Our study demonstrates how the combination of modelled and observed communities provides a framework for the generation of hypothesis about abiotic geochemical processes as well as the overall distribution of functional groups of microbial primary producers. Future investigations, including rate measurements and modern omics technology, seem to be a promising path to further elucidate the importance of energy availability in these environments and how different functional groups are energetically connected. It should be realized that hydrothermal systems are excellent natural laboratories for investigations of general ecological principles regarding relationships between energy availability and the distribution of functional groups of organisms in biological communities.

\section{Conflict of Interest}

The authors declare no conflict of interest.

\section{Acknowledgements}

This work was supported by the Research Council of Norway (Project number 179560). We thank Frida Lise Daae at the Centre for Geobiology for assistance in generating $16 \mathrm{~S}$ rRNA gene amplicons. We thank three anonymous reviewers for their constructive comments.

\section{References}

Altschul SF, Madden TL, Schäffer AA, Zhang J, Zhang Z, Miller W et al. (1997). Gapped BLAST and PSI-BLAST: a new generation of protein database search programs. Nucleic Acids Res 25: 3389-3402.

Amend JP, McCollom TM, Hentscher M, Bach W. (2011). Catabolic and anabolic energy for chemolithoautotrophs in deep-sea hydrothermal systems hosted in different rock types. Geochim Cosmochim Acta 75: 5736-5748.

Amend JP, Rogers KL, Shock EL, Gurrieri S, Inguaggiato S. (2003). Energetics of chemolithoautotrophy in the hydrothermal system of Vulcano Island, southern Italy. Geobiology 1: 37-58.

Barns SM, Delwiche CF, Palmer JD, Pace NR. (1996). Perspectives on archaeal diversity, thermophily and monophyly from environmental rRNA sequences. Proc Natl Acad Sci USA 93: 9188-9193.

Baumberger T. (2011). Volatiles in Marine Hydrothermal Systems, Ph.D. thesis. ETH Zürich: Zürich, Switzerland.

Brazelton WJ, Schrenk MO, Kelley DS, Baross JA. (2006). Methane- and sulfur-metabolizing microbial communities dominate the Lost City hydrothermal field ecosystem. Appl Environ Microbiol 72: 6257-6270.

Campbell BJ, Engel AS, Porter ML, Takai K. (2006). The versatile $\varepsilon$-proteobacteria: key players in sulphidic habitats. Nat Rev Microbiol 4: 458-468.

Dahle H, Roalkvam I, Thorseth IH, Pedersen RB, Steen IH. (2013). The versatile in situ gene expression of an Epsilonproteobacteria-dominated biofilm from a hydrothermal chimney. Environ Microbiol Rep 5: 282-290.

Dick JM. (2008). Calculation of the relative metastabilities of proteins using the CHNOSZ software package. Geochem Trans 9: 10.

Duperron S, Bergin C, Zielinski F, Blazejak A, Pernthaler A, McKiness ZP et al. (2006). A dual symbiosis shared by two mussel species, Bathymodiolus azoricus and Bathymodiolus puteoserpentis (Bivalvia: Mytilidae), from hydrothermal vents along the northern Mid-Atlantic Ridge. Environ Microbiol 8: 1441-1447.

Foustoukos DI, Houghton JL, Seyfried Jr WE, Sievert SM, Cody GD. (2011). Kinetics of $\mathrm{H}_{2}-\mathrm{O}_{2}-\mathrm{H}_{2} \mathrm{O}$ redox-equilibria and formation of metastable $\mathrm{H}_{2} \mathrm{O}_{2}$ under low temperature hydrothermal conditions. Geochim Cosmochim Acta 75: 1594-1607.

Gotz D, Banta A, Beveridge TJ, Rushdi AI, Simoneit BRT, Reysenbach A. (2002). Persephonella marina gen. nov., sp nov and Persephonella guaymasensis sp nov., two novel, thermophilic, hydrogen-oxidizing microaerophiles from deep-sea hydrothermal vents. Int J Syst Evol Microbiol 52: 1349-1359.

Haroon MF, Hu S, Shi Y, Imelfort M, Keller J, Hugenholtz P et al. (2013). Anaerobic oxidation of methane coupled to nitrate reduction in a novel archaeal lineage. Nature 500: $567-570$.

Heijs SK, Haese RR, van der Wielen PWJJ, Forney LJ, van Elsas JD. (2007). Use of $16 \mathrm{~S}$ rRNA gene based clone libraries to assess microbial communities potentially involved in anaerobic methane oxidation in a Mediterranean cold seep. Microb Ecol 53: 384-398.

Helgeson HC. (1969). Thermodynamics of hydrothermal systems at elevated temperatures and pressures. Am J Sci 267: 729-804.

Hirayama H, Fuse H, Abe M, Miyazaki M, Nakamura T, Nunoura T et al. (2013). Methylomarinum vadi gen. nov., sp nov., a methanotroph isolated from two distinct marine environments. Int J Syst Evol Microbiol 63: 1073-1082.

Holler T, Widdel F, Knittel K, Amann R, Kellermann MY, Hinrichs K-U et al. (2011). Thermophilic anaerobic oxidation of methane by marine microbial consortia. ISME J 5: 1946-1956.

Houghton JL, Seyfried SE. (2010). An experimental and theoretical approach to determining linkages between geochemical variability and microbial biodiversity 
in seafloor hydrothermal chimneys. Geobiology 8: 457-470.

Jannasch HW, Mottl MJ. (1985). Geomicrobiology of deep-sea hydrothermal vents. Science 229: 717-725.

Johnson JW, Oelkers EH, Helgeson HC. (1992). SUPCRT92: A software package for calculating the standard molal thermodynamic properties of minerals, gases, aqueous species, and reactions from 1 to 5000 bar and 0 to 1000 ${ }^{\circ}$ C. Comput Geosci 18: 899-947.

Kadko DC, Rosenberg ND, Lupton JE, Collier RW, Lilley MD. (1990). Chemical reaction rates and entrainment within the Endeavour Ridge hydrothermal plume. Earth Planet Sci Lett 99: 315-335.

Kato S, Yanagawa K, Sunamura M, Takano Y, Ishibashi J-I, Kakegawa T et al. (2009). Abundance of Zetaproteobacteria within crustal fluids in back-arc hydrothermal fields of the Southern Mariana Trough. Env Microbiol 11: 3210-3222.

Kubo K, Lloyd KG, Biddle JF, Amann R, Teske A, Knittel K. (2012). Archaea of the miscellaneous Crenarchaeotal Group are abundant, diverse and widespread in marine sediments. ISME J 6: 1949-1965.

Lam P, Cowen JP, Popp BN, Jones RD. (2008). Microbial ammonia oxidation and enhanced nitrogen cycling in the Endeavour hydrothermal plume. Geochim Cosmochim Acta 72: 2268-2286.

Lane DJ, Pace B, Olsen GJ, Stahl DA, Sogin ML, Pace NR. (1985). Rapid determination of $16 \mathrm{~S}$ ribosomal RNA sequences for phylogenetic analyses. Proc Natl Acad Sci USA 82: 6955-6959.

Lanzen A, Jørgensen SL, Huson DH, Gorfer M, Grindhaug SH, Jonassen I et al. (2012). CRESTClassification Resources for Environmental Sequence Tags. PLoS One 7: e49334.

LaRowe DE, Amend JP. (2014). Energetic constraints on life in deep marine sediments. In Kallmeyer J, Wagner $\mathrm{K}$ (eds), Life in Extreme Environments: Microbial Life in the Deep Biosphere. De Gruyter Publishing: Berlin, pp 279-302.

LaRowe DE, Dale AW, Aguilera DR, L'Heureux I, Amend JP, Regnier P. (2014). Modeling microbial reaction rates in a submarine hydrothermal vent chimney wall. Geochim Cosmochim Acta 124: 72-97.

Li H, Yang S-Z, Mu B-Z. (2007). Phylogenetic diversity of the archaeal community in a continental high-temperature, water-flooded petroleum reservoir. Curr Microbiol 55: 382-388.

Lilley MD, Butterfield DA, Olson EJ, Lupton JE, Macko SA, McDuff RE. (1993). Anomalous $\mathrm{CH}_{4}$ and $\mathrm{NH}_{4}^{+}$concentrations at an unsedimented Mid-Oceanridge hydrothermal system. Nature 364: 45-47.

Majzlan J, Navrotsky A, Schwertmann U. (2004). Thermodynamics of iron oxides: Part III. Enthalpies of formation and stability of ferrihydrite $\left(\sim \mathrm{Fe}(\mathrm{OH})_{3}\right)$, schwertmannite $\left(\sim \mathrm{FeO}(\mathrm{OH})_{3 / 4}\left(\mathrm{SO}_{4}\right)_{1 / 8}\right)$, and $\varepsilon-\mathrm{Fe}_{2} \mathrm{O}_{3}$. Geochim Cosmochim Acta 68: 1049-1059.

McCollom TM. (2000). Geochemical constraints on primary productivity in submarine hydrothermal vent plumes. Deep-Sea Res I 47: 85-101.

McCollom TM. (2007). Geochemical constraints on sources of metabolic energy for chemolithoautotrophy in ultramafic-hosted deep-sea hydrothermal systems. Astrobiology 7: 933-950.

McCollom TM, Shock EL. (1997). Geochemical constraints on chemolithoautotrophic metabolism by microorganisms in seafloor hydrothermal systems. Geochim Cosmochim Acta 61: 4375-4391.
Merkel AY, Huber JA, Chernyh NA, Bonch-Osmolovskaya EA, Alexander V, Lebedinskya AV. (2013). Detection of putatively thermophilic anaerobic methanotrophs in diffuse hydrothermal vent fluids. Appl Environ Microbiol 79: 915-923.

Meyer-Dombard DR, Shock EL, Amend JP. (2005). Archaeal and bacterial communities in geochemically diverse hot springs of Yellowstone National Park, USA. Geobiology 3: 211-227.

Oksanen J, Blanchet FG, Kindt R, Legendre P, O’Hara RB, Simpson GL et al. (2011). Vegan: Community Ecology Package. R package version 1.17-6. Available at: http:// CRAN.R-project.org/package=vegan. Last accessed in October 2014.

Parkes RJ, Webster G, Cragg BA, Weightman AJ, Newberry CJ, Ferdelman TG et al. (2005). Deep sub-seafloor prokaryotes stimulated at interfaces over geological time. Nature 436: 390-394.

Pedersen RB, Rapp HT, Thorseth IH, Lilley MD, Barriga FJAS, Baumberger T et al. (2010b). Discovery of a black smoker vent field and vent fauna at the Arctic Mid-Ocean Ridge. Nat Commun 1: 1-6.

Pedersen RB, Thorseth IH, Nygård TE, Lilley MD, Kelley DS. (2010a). Hydrothermal activity at the Arctic Mid-Ocean Ridges. In Rona PA, Devey CW, Dyment J, Murton BJ (eds), Diversity of Hydrothermal Systems on Slow Spreading Ocean Ridges. American Geophysical Union: Washington, DC, USA, pp 67-89.

Quince C, Lanzen A, Davenport R, Turnbaugh P. (2011). Removing noise from pyrosequenced amplicons. $B M C$ Bioinform 12: 38.

Roalkvam I, Jørgensen SL, Chen Y, Stokke R, Dahle H, Hocking WP et al. (2011). New insight into stratification of anaerobic methanotrophs in cold seep sediments. FEMS Microbiol Ecol 78: 233-243.

Roesch LFW, Fulthorpe RR, Riva A, Casella G, Hadwin AKM, Kent $\mathrm{AD}$ et al. (2007). Pyrosequencing enumerates and contrasts soil microbial diversity. ISME $J \quad$ 1: 283-290.

Rogers KL, Amend JP. (2005). Archaeal diversity and geochemical energy yields in a geothermal well on Vulcano Island, Italy. Geobiology 3: 319-332.

Rogers KL, Amend JP. (2006). Energetics of potential heterotrophic metabolisms in the marine hydrothermal system of Vulcano Island, Italy. Geochim Cosmochim Acta 70: 6180-6200.

Rogers KL, Amend JP, Gurrieri S. (2007). Temporal changes in fluid chemistry and energy profiles in the Vulcano island hydrothermal system. Astrobiology 7: 905-932.

Seewald J, Cruse A, Saccocia P. (2003). Aqueous volatiles in hydrothermal fluids from the Main Endeavour Field, northern Juan de Fuca Ridge: temporal variability following earthquake activity. Earth Planet Sci Lett 216: 575-590.

Seyfried WE, Seewald JS, Berndt ME, Ding K, Foustoukos DI. (2003). Chemistry of hydrothermal vent fluids from the Main Endeavour Field, northern Juan de Fuca Ridge: geochemical controls in the aftermath of June 1999 seismic events. J Geophys Res 108; doi:10.1029/ 2002JB001957.

Shock EL, Holland M, Meyer-Dombard D, Amend JP, Osburn GR, Fischer TP. (2010). Quantifying inorganic sources of geochemical energy in hydrothermal ecosystems, Yellowstone National Park, USA. Geochim Cosmochim Acta 74: 4005-4043. 
Shock EL, Holland ME. (2004). Geochemical energy sources that support the subsurface biosphere. In Wilcock D, DeLong EF, Kelley DS, Baross JA, Cary SC (eds), The Subsurface Biosphere at Mid-Ocean Ridges. American Geophysical Union: Washington, DC, USA, pp 153-165.

Snow CL, Lilova KI, Radha AV, Shi Q, Smith S, Navrotsky A et al. (2013). Heat capacity and thermodynamics of a synthetic two-line ferrihydrite, $\mathrm{FeOOH} \cdot 0.027 \mathrm{H}_{2} \mathrm{O}$. J Chem Thermodyn 58: 307-314.

Spear JR, Walker JJ, McCollom TM, Pace NR. (2005). Hydrogen and bioenergetics in the Yellowstone geothermal ecosystem. Proc Natl Acad Sci USA 102: $2555-2560$.

Teske A, Hinrichs KU, Edgcomb V, Gomez AD, Kysela D, Sylva SP et al. (2002). Microbial diversity of hydrothermal sediments in the Guaymas Basin: evidence for anaerobic methanotrophic communities. Appl Environ Microbiol 68: 1994-2007.
Tivey MK. (1995). The influence of hydrothermal fluid composition and advection rates on black smoker chimney mineralogy: Insights from modeling transport and reaction. Geochim Cosmochim Acta 59: 1933-1949.

(1) $(\Theta)$ This work is licensed under a Creative (c) ${ }_{\text {BV }}$ Ne $\mathrm{ND}$ Commons Attribution-NonCommercialNoDerivs 3.0 Unported License. The images or other third party material in this article are included in the article's Creative Commons license, unless indicated otherwise in the credit line; if the material is not included under the Creative Commons license, users will need to obtain permission from the license holder to reproduce the material. To view a copy of this license, visit http://creativecommons.org/licenses/bync-nd/3.0/

Supplementary Information accompanies this paper on The ISME Journal website (http://www.nature.com/ismej) 